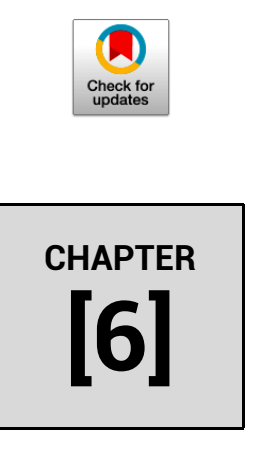

In: Environmental Degradation: Causes and Remediation Strategies

DOI: 10.26832/aesa-2020-edcrs-06

\title{
Alkalotolerant consortium as a potential degrader of dioxin-like compounds of pulp and paper mill wastewater
}

\author{
Shweta Sahni \\ Department of Microbiology, School of Basic and Applied Sciences, \\ Shri Guru Ram Rai University, Dehradun-248001, Uttarakhand, India
}

Nowadays, the industrialized world is confronted with the contamination of soils, water sources, and air with hazardous and toxic xenobiotics. Polycyclic aromatic hydrocarbons (PAHs) are toxic pollutants that have accumulated in the environment due to a variety of anthropogenic activities. In this study, an alkalotolerant bacterial consortium was developed by continuous enrichment in the chemostat in presence of dibenzofuran (DBF) as sole carbon source. Six different types of bacterial isolates were isolated on agar plates. Among the six isolates tested for degradation of $\mathrm{DBF}$, strain $\mathrm{C}$ of alkalotolerant bacterial community had better potency to degrade dibenzofuran. Alkalotolerant bacterial consortia introduced in soil microcosm for evaluation of survival of most suitable isolates and degradation of dioxin-like compound indicated more than $90 \%$ degradation of dibenzofuran after 45 days by the bacterial consortia enriched for 180 days in the chemostat at $\mathrm{pH}$ 10, however, microbial community, not enriched in the chemostat, was not competent to utilize even $50 \% \mathrm{DBF}$ after day 30 . This suggests that the microbial community adapted for a longer time in chemostat had better efficiency for the degradation of DBF. Degradation of dibenzofuran in soil microcosm indicates that the community is competent enough to survive and retain its degrading potency even in-situ conditions.

\section{KEYWORDS}

Alkalotolerant, Dibenzofuran, Consortia, Degradation, Microcosm

Shweta Sahni, Email: drshwetasahni@gmail.com

(c) 2020 | Agro Environ Media | Agriculture and Environmental Science Academy, Haridwar, India 


\section{Introduction}

Pollution of the environment has been one of the largest concerns for science and the general public in the last years. Nowadays, the industrialized world is confronted with the contamination of soils, water sources, and air with hazardous and toxic xenobiotics. Polycyclic aromatic hydrocarbons (PAHs) are toxic pollutants that have accumulated in the environment due to a variety of anthropogenic activities (Barkovskii and Adriaens, 1996). Bioremediation using various microorganisms is one of the approaches tested for the removal of PAHs from the environment. Bioremediation is a process by which living organisms degrade or transform hazardous organic contaminants to less toxic compounds (Arun et al., 2008). Halogenated dibenzo-p-dioxin and dibenzofuran are the most toxic group of persistent organic pollutants (POPs) having carcinogenic, immunosuppressive, endocrine disruptive and teratogenic properties (Adriaens et al., 1996; Mandal, 2005). Dioxins are an unintentional by-product of various industrial activities. Pulp and paper industry is one of the major sources for dioxin contamination (Thacker et al., 2007). Very few microbial strains have the capability to metabolize dioxin-like compounds due to its planar structure, acute hydrophobicity, less bioavailability (Nojiri and Omori, 2002). Many bacterial strains, Pseudomonas sp. strain HH69 (Fortnagel et al., 1990); Brevibacterium sp. strain DPO 1361 (Strubel et al., 1989; Strubel et al., 1991), Sphingomonas sp. strain RW1 (Wittich et al., 1992), Pseudomonas aeruginosa and Xanthomonas maltophilia (Ishiguro et al., 2000), Terrabacter sp. strain YK3 (Iida et al., 2002), Serratia marcescens (Jaiswal and Thakur, 2007) and Pseudomonas sp. strain ISTDF1 (Jaiswal et al., 2011) have been isolated and catabolic potential for degradation of dibenzofuran has been evaluated. But very few reports are available for in-situ bioremediation of dioxin-like compounds in the environment (Haack et al., 1995; Kumar et al., 2019).

The highly alkaline nature of industrial effluent necessitates the search for bacteria that can survive and degrade dioxin in such extreme conditions. Because of the relatively low cost and minimal impact on the environment, dioxin degrading bacteria have been isolated by using dibenzofuran (DF) as a model substrate in enrichment culture (Fortnagel et al., 1996). The indigenous community is the actual player which persistently exists in such a hostile environment. Gradual adaptation of native bacteria under increasing alkaline conditions could be useful for efficient in-situ bioremediation of dioxin including other persistent organic pollutants (POPs) (Kao et al., 2001). The bioremediation of dioxin-like compounds under alkaline conditions is of interest because the alkalinity of effluent will change gradually after release in the environment which is a very critical factor for biodegradation. In addition, they have higher sorption capability in soil, and toxicity decreases as $\mathrm{pH}$ increases, owing to the increased conversion of undissociated (more toxic) to the dissociated form (Kishino and Bayashi, 1995). In general, populations of bacteria decline the following introduction into natural soil and the 
growth of introduced populations is poor in microbiologically undisturbed soil. For successful bioaugmentation, there is the need to identify, and properly manage, the environmental conditions controlling the survival and activity of introduced micro-organisms. Microcosms are used to study biodegradation and the fate and effect of introduced micro-organisms (WagnerDo "bler et al., 1992). This can lead to a better understanding of the effect of factors controlling soil microbial inoculation, especially with regard to indigenous micro-organisms and to study the capability of inoculated micro-organisms to degrade certain chemicals.

\section{Study area}

Sludge effluent and sediment samples were collected from Century pulp and paper mill, Lalkua, Nainital, Uttaranchal, India $\left(29^{\circ} 24^{\prime} \mathrm{N}, 79^{\circ} 28^{\prime} \mathrm{E}\right)$. The site was effluent discharging canals and premises of the industry. The sludge with liquid effluent was collected in clean plastic bags and stored at $4^{\circ} \mathrm{C}$ in a refrigerator until used for further analysis.

\section{Characterization of effluent}

The effluent was characterized for various physical and chemical parameters like $\mathrm{pH}$, temperature, TDS, TSS, color, DO, BOD, COD and lignin content. $\mathrm{pH}$ was measured with the help of $\mathrm{pH}$ meter (Cyberscan 51), temperature by using portable digital multi-stem thermometer (Hanna Instrument Co. Italy) with external sensing probe on the sampling sites, TDS and TSS were estimated as described in APHA (2005), color by 2120 C Cobalt-platinate method (APHA, 2005), DO (Wrinkler's method), COD (5220 B open reflux method) and BOD were estimated as per APHA (2005). Lignin content was estimated according to Pearl and Benson (1940). Dibenzofuran was detected by GC-MS as described later.

\section{Chemostat: enrichment of bacterial consortium}

The reactor vessel consists of a $22 \times 7 \mathrm{~cm}$ glass vessel, effective volume 1 litre, provided with an inlet for the entry of fresh sterile medium and an outlet for the removal of spent medium. Another inlet was provided specifically for the alkaline solution which maintained the $\mathrm{pH}$ of culture from 7 to 10 . Sterile air was passed into the culture vessel by way of using aeration pump and sinister glass filter. The culture vessel was kept over a magnetic stirrer which was capable of maintaining the temperature at $28^{\circ} \mathrm{C}$ to $30^{\circ} \mathrm{C}$. The composition of mineral salt medium $(\mathrm{g} / \mathrm{l})$ was: $\mathrm{Na}_{2} \mathrm{HPO}_{4}, 2 \mathrm{H}_{2} \mathrm{O}$. 7.8; $\mathrm{KH}_{2} \mathrm{PO}_{4}, 6.8 ; \mathrm{MgSO}_{4}, 0.2$, ammonium ferric acetate, 0.01; $\mathrm{Ca}\left(\mathrm{NO}_{3}\right)_{2}, 4 \mathrm{H}_{2} \mathrm{O}$, $0.05 ; \mathrm{NaNO}_{3}, 0.085$, trace element solution with 4-chlorosalicyclic acid (CSA) (5Mm) / dibenzofuran $(1 \mathrm{Mm})$ as described (Thakur, 1995). The sediment and sludge containing bacterial cell populations served as inoculum in the chemostat. Initially, the bacteria were adapted in the presence of 4-CSA. After stabilization of the bacterial growth as determined by O.D. at $595 \mathrm{~nm}$, the CSA in the medium was replaced by DBF (dibenzofuran). The $\mathrm{pH}$ of the chemostat was 
gradually increased from $\mathrm{pH} 7$ to $\mathrm{pH} 10$. The culture medium was collected from chemostat at $\mathrm{pH}$ $7,8,9$, and 10 after stabilization of the bacterial growth determined by O.D. at $595 \mathrm{~nm}$. Four samples thus collected were centrifuged at $7000 \mathrm{rpm}$ for $10 \mathrm{~min}$. The bacterial pellet thus obtained was used for the determination of DBF utilization.

\section{Monitoring of substrate depletion by gas chromatography}

Utilization of dibenzofuran was tested in Erlenmeyer flasks containing mineral salt medium supplemented with $1 \mathrm{mM}$ dibenzofuran (DBF crystals dissolved in dimethylsulfoxide, $100 \mathrm{mg} / \mathrm{L}$ ) as the sole source of carbon and energy, and incubated at $30^{\circ} \mathrm{C}$ on an orbital shaker at $150 \mathrm{rpm}$. The samples were removed after $0,6,12,24,48,120 \mathrm{~h}$ growth of bacterial strains and the utilization of carbon source was determined. Bacterial cells were removed by centrifugation at $7000 \mathrm{rpm}$ for $10 \mathrm{~min}$. DBF concentration was determined by gas chromatography (GC). The culture medium $(25 \mathrm{ml})$ was dissolved in DMSO and then extracted with double volume ethyl acetate (Jaiswal and Thakur, 2007). The organic phase (extract) was separated by a separating funnel, and the extract was finally concentrated on a rotary evaporator. Ethyl acetate was evaporated and the residue was re-dissolved in $100 \mu \mathrm{l}$ ethyl acetate. The concentration of DBF was identified by using gas chromatography (GC) (GCPerkin Elmer) equipped with a capillary column (DB5 MS; $30 \mathrm{~m} \cdot 0.25 \mathrm{~mm}$ film thickness $\cdot 0.25 \mathrm{~mm}$ I.D. $\cdot 30 \mathrm{~m}$ long). One $\mu$ l of each extract was analyzed by GC at condition (splitless mode; initial temperature $80^{\circ} \mathrm{C}$ for $1.5 \mathrm{~min}$; temperature increased $80-230^{\circ} \mathrm{C}$ at a rate of $20^{\circ} \mathrm{C} \mathrm{min}-1$ and 230 to $250^{\circ} \mathrm{C}$ and kept it at $250{ }^{\circ} \mathrm{C}$ for $4.5 \mathrm{~min})$.

\section{Isolation of bacteria from chemostat sample at $\mathbf{p H} \mathbf{1 0}$}

The enriched bacterial community from chemostat at $\mathrm{pH} 10$ was diluted in tenfold serial dilution and spread on LB-agar plates. After $14 \mathrm{hrs}$ incubation, colonies that appeared on Luria Bertani agar plates were characterized by morphological observation. Six dominant and morphologically distinct colonies were isolated.

\section{Survival pattern of each strain}

Morphologically distinct colonies were isolated and inoculated in MSM (Minimal Salt Medium) having dibenzofuran $(1 \mathrm{mM})$ dissolved in DMSO. Survival pattern of each colony was drawn on the basis of absorbance at 595nm on spectrophotometer Cary, 100 Bio (Varian Co., Australia) as described by Fortnagel et al. (1990). DBF utilization by each strain was determined by gas chromatography (Jaiswal and Thakur, 2007).

\section{Bacterial growth and culture conditions}

After adaptation in a chemostat, the bacterial consortium obtained at $\mathrm{pH} 10$ was inoculated in 
Luria Bertani medium at 5\% (v/v). The culture was incubated till 1.0 optical density (OD) at 595 $\mathrm{nm}$ and then centrifuged at 6000 rotation per minute (rpm) for 6 minutes at $4^{\circ} \mathrm{C}$. The bacterial pellet, thus obtained, was transferred to the minimal salt medium with dibenzofuran ( $1 \mathrm{mM})$ at $\mathrm{pH} 10$ for agitation in the orbital shaker. After 6, 12, 18, 24, 30 and 36 hours, samples were collected and OD was measured at $595 \mathrm{~nm}$. MSM samples were centrifuged at $6000 \mathrm{rpm}$ for 6 minutes. Its supernatant was taken for biodegradation studies.

\section{Utilization of dibenzofuran}

Culture supernatant was extracted with double volume ethyl acetate and split it into two equal volumes. One was acidified with $6 \mathrm{~N} \mathrm{HCl}$ to approximately $\mathrm{pH} 2.0$ and other at $\mathrm{pH} 7$ (Jaiswal and Thakur, 2007). The organic phase (extract) was separated by a separating funnel, and the extract was finally concentrated on a rotary evaporator. Ethyl acetate was evaporated and the residue was re-dissolved in $100 \mu \mathrm{l}$ acetonitrile. The concentration of DBF was identified by using gas chromatography (GC) (GC-Perkin Elmer) equipped with a capillary column (DB5; $0.25 \mathrm{mM}$ film thickness $\cdot 0.25 \mathrm{~mm}$ Internal diameter. 30 meters long). One $\mu \mathrm{l}$ of each extract was analyzed by GC at condition (splitless mode; initial temperature $80^{\circ} \mathrm{C}$ for $1.5 \mathrm{~min}$; temperature increased 80 $230^{\circ} \mathrm{C}$ at a rate of $20^{\circ} \mathrm{C} \mathrm{min}-1$ and 230 to $250^{\circ} \mathrm{C}$ and kept it at $250{ }^{\circ} \mathrm{C}$ for $4.5 \mathrm{~min}$ ). Concentration was derived from the standard plot between peak area and concentration of DBF.

\section{Microcosm soil analysis}

The soil moisture content, water holding capacity (WHC), and $\mathrm{pH}$ were determined as described previously by Vinas et al. (2005). To determine the best soil water content for use in the microcosm experiments, five different water contents (5\%, 20\%, 40\%, 60\%, and 75\% WHC) and autoclaved soil as an abiotic control were assayed for 15 days in triplicate in miniaturized microcosms. The best results were observed with $60 \%$ WHC (70\% biodegradation of DBF). Thus, water content was established as a key factor for biodegradation activity, and $60 \%$ WHC was defined as the optimal water content for soil microcosm experiments.

\section{Microcosm design}

Microcosms were prepared according to Gautam et al. (2003) and modified as follows: soil grits (100 gm) were placed on the bottom of a sealed plastic jar, then sand (100 gm) formed the middle layer and soil $(300 \mathrm{gm})$ formed the top later. Experiments were performed using sterile soil and non-sterile soil. Eight sets of microcosms were prepared as described in Table 1. The soil was treated as described by Megharaj et al. (1997). Four sets of soil microcosms were sterilized by autoclaving at $121{ }^{\circ} \mathrm{C}$ for $45 \mathrm{~min}$ on three consecutive days. Sterility was checked afterward by streaking dilutions of soil suspensions on LB agar plates. Sterile soil and non-sterile soil were then treated with either DBF at a final concentration of $1 \mathrm{mg} / \mathrm{g}$ soil from $50-\mathrm{mg} / \mathrm{ml}$ stock solutions 
Table 1. Microcosms inoculated with the bacterial community which is non-adapted or adapted at different $\mathrm{pH}$ levels.

\begin{tabular}{ll}
\hline Label & Description \\
\hline A & Control with Unautoclaved soil \\
B & Control with Autoclaved soil \\
C & Unadapted Bacterial Community + Unautoclaved soil \\
D & Unadapted Bacterial Community + Autoclaved soil \\
E & Bacterial Community Adapted at pH $7.0+$ Unautoclaved soil \\
F & Bacterial Community Adapted at pH $7.0+$ Autoclaved soil \\
G & Bacterial Community Adapted at pH $10.0+$ Unautoclaved soil \\
H & Bacterial Community Adapted at pH $10.0+$ Autoclaved soil \\
\hline
\end{tabular}

made in analytical grade acetone. The acetone solvent was evaporated and soils were rigorously mixed and allowed to equilibrate at $25^{\circ} \mathrm{C}$ for $6 \mathrm{~h}$. Controls were similarly treated with acetone. Microcosms containing non-sterile soil were pre-incubated at $30^{\circ} \mathrm{C}$, prior to the experiment, to allow the indigenous microorganisms to reach an equilibrium state, avoiding a thermal artifact at time zero of the experiment (Lafuente et al., 1996). Bacteria were grown with shaking at $30^{\circ} \mathrm{C}$ in Luria-Bertani (LB) broth to the late exponential phase. Cells were harvested by centrifugation, resuspended in mineral salt medium and then inoculated in the soil at a level of $10^{7}-10^{8} \mathrm{cells} / \mathrm{g}$ dry soil, partly following recommendations of Comeau et al. (1993). Sterile distilled water was added to the soil to reach a final moisture content of $60 \%(\mathrm{v} / \mathrm{wt})$, rigorously mixed and kept at $30^{\circ} \mathrm{C}$.

\section{Sampling}

Chemical, microbial, and molecular analyses were carried out on sampling days $0,03,07,15,30$, 45 , and 90. At each sampling time, $25 \mathrm{~g}$ of soil was extracted as a composite sample from five points in each microcosm and stored at $-20^{\circ} \mathrm{C}$ prior to most analyses; the only exception was microbial counting, which was performed immediately after sampling.

\section{Monitoring the depletion of dibenzofuran in soil microcosm}

The extraction of metabolites was performed by a modified method described by Jaiswal and Thakur (2007). $25 \mathrm{ml}$ of acetonitrile with $2 \% \mathrm{H}_{3} \mathrm{PO}_{4}$ was added to $10 \mathrm{gm}$ of soil and agitated for 60 min. The particles were settled down, and the supernatant was passed through a polytetrafluoroethylene membrane filter $(0.2 \mu \mathrm{m})$. One $\mu \mathrm{l}$ of each extract was analyzed by Gas chromatographymass spectroscopy (GC-MS) (Varian) equipped with a capillary column (DB5 MS; 30m $\times 0.25 \mathrm{um}$ film thickness $\times 0.25 \mathrm{~mm}$ I.D. $\times 30$ meter long) at splitless mode; initial temperature $80^{\circ} \mathrm{C}$ for 1.5 min; temperature increased from 80 to $230^{\circ} \mathrm{C}$ at a rate of $20^{\circ} \mathrm{C} / \mathrm{min}$ and 230 to $250^{\circ} \mathrm{C}$ and kept it 
at $250^{\circ} \mathrm{C}$ for $4.5 \mathrm{~min}$. The head pressure of the helium carrier gas was $80 \mathrm{kPa}$ helium flow rate $1.1 \mathrm{ml} / \mathrm{min}$ as described by lida et al. (2002).

\section{Physical and chemical properties of effluent}

The effluent collected from pulp and paper industry, Lalkuan, Uttarakhand showed the following physical and chemical characteristics. It was dark in color with high COD, BOD and DO and was alkaline in nature. The effluent was found to be contaminated with dibenzofuran (2 ppm) (Table 2). Each value represents the mean of three replicates \pm SEM.

\section{Utilization of dibenzofuran by the bacterial community at different $\mathrm{pH}$}

The effluent from the industry was used as inoculum in chemostat containing MSM with CSA, followed by MSM with DBF where the bacterial community was adapted for a $\mathrm{pH}$ range from 7 to 10. Samples collected at each $\mathrm{pH}$ were inoculated in MSM with DBF and monitored for the depletion of DBF. Gas Chromatogram of samples collected from MSM at different time intervals revealed adaptation has enhanced the degradation ability of the indigenous bacteria. Adapted culture degraded more dibenzofuran than non-adapted culture. While non-adapted culture degraded only 35\% DBF in 264 hrs, culture adapted at pH 7 degraded 45\%, pH 8 degraded 50\%, and $\mathrm{pH} 9$ degraded $70 \%$. The culture at $\mathrm{pH} 10$ showed maximum degradation potential, which is more than $90 \%$ in 264 hrs (Figure 1).

\section{Isolation of bacteria from $\mathrm{pH} 10$ sample}

The sample collected of $\mathrm{pH} 10$ culture was used as inoculum to spread on LB plates. Six colonies were selected on the basis of morphological differences. The colonies were labeled as Strain A,

Table 2. Physico-chemical characterization of effluent used in this study.

\begin{tabular}{ll}
\hline Parameter & Value \\
\hline pH & $10.4 \pm 0.2$ \\
Temperature & $30.5 \pm 01^{\circ} \mathrm{C}$ \\
TDS (mg l-1) & $1243 \pm 11.3$ \\
TSS (mg l-1) & $285.9 \pm 1.9$ \\
Color of effluent (coloring units) & $62385 \pm 70.23$ \\
DO (in ppm) & $0.0 \pm 0.0$ \\
BOD (in ppm) & $53216 \pm 13$ \\
COD (in ppm) & $204358 \pm 81.20$ \\
Lignin (in ppm) & $153741 \pm 91.20$ \\
Dibenzofuran (in ppm) & $2.00 \pm 0.32$ \\
\hline
\end{tabular}




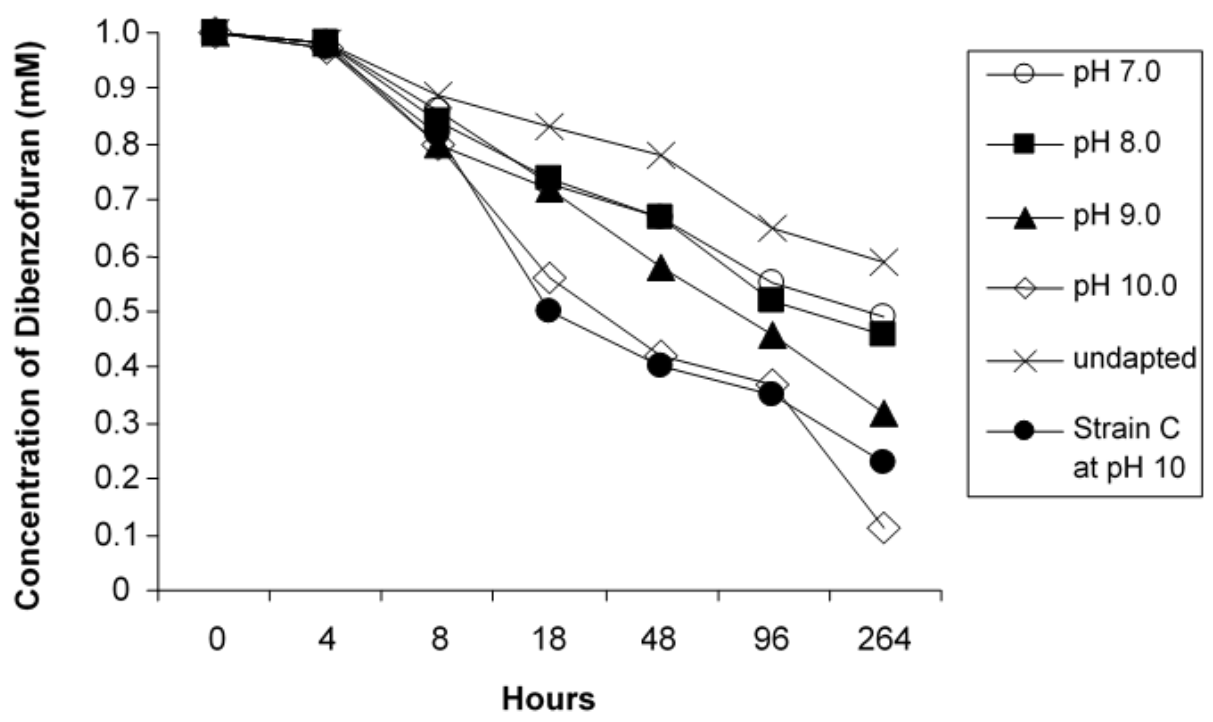

Figure 1. Comparison of utilization of dibenzofuran by total bacterial community enriched at gradually increasing $\mathrm{pH}$

Strain B, Strain C, Strain D, Strain E, Strain F.

\section{Utilization of dibenzofuran}

The utilization of dibenzofuran by all six strains was then analyzed. Each strain was inoculated in MSM containing DBF and samples were collected at different time intervals and the concentration of DBF was calculated by peak formed during GC. The concentration of DBF was plotted against the time interval as shown in Figure 2. The survival pattern of each strain was also estimated and Strain C was found to be most effective. It degraded approximately 50\% DBF in $260 \mathrm{hrs}$. As shown in Figure 2, strain $C$ gives a maximum peak of absorbance indicating maximum growth. Strains $\mathrm{A}$ and $\mathrm{F}$ were found to be least effective on DBF while strains B, D, and E gave good results.

Thus, the bacterial community obtained through chemostat was found to be capable of growing and degrading DBF at $\mathrm{pH} 10$. The community consists of strains $\mathrm{A}, \mathrm{B}, \mathrm{C}, \mathrm{D}, \mathrm{E}$, and F. Among which strain $C$ was found to be most potent DBF degrader followed by B, D and E. Strains A and $\mathrm{F}$ were not found to be efficient DBF degrader. Still, they are present in the stable bacterial community. This indicates that they might be involved in the degradation of lower metabolites. 

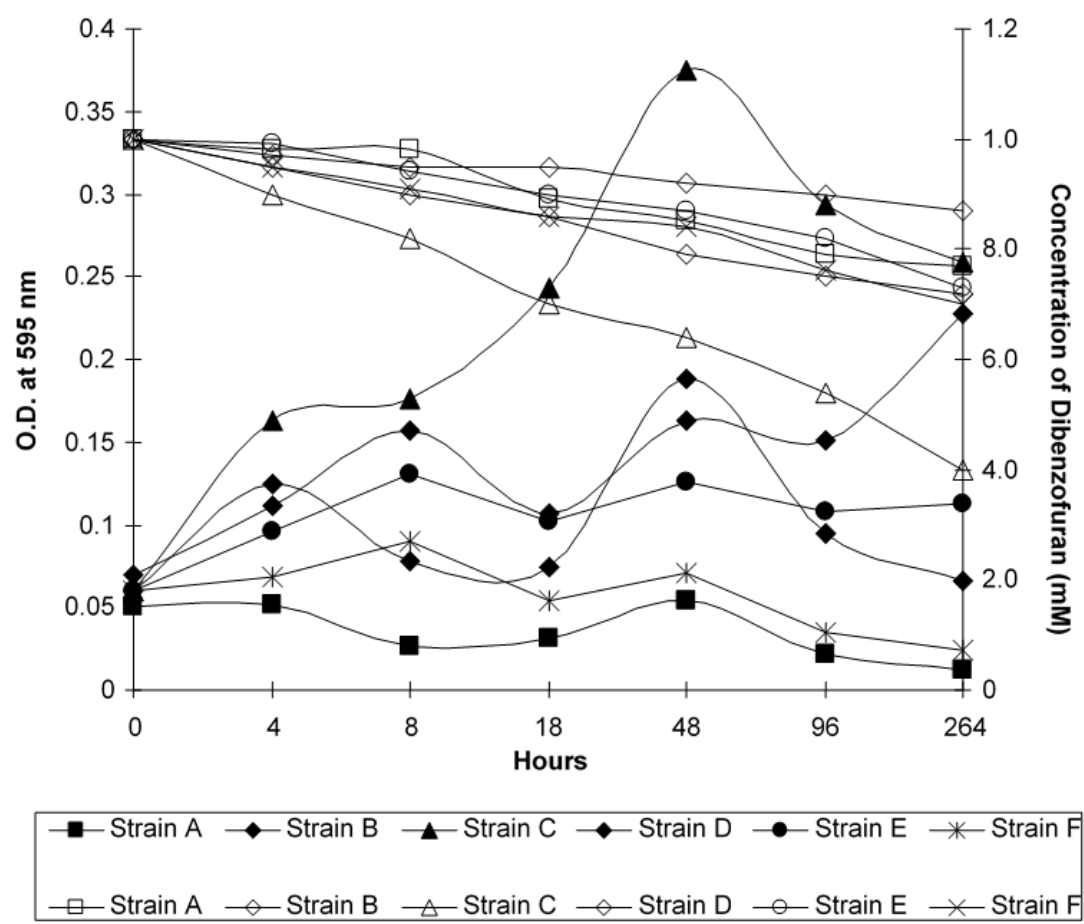

Figure 2. Growth pattern of six bacterial isolates from pulp and paper industry effluent determined at $595 \mathrm{~nm}$. pH 7.0. A, B, C, D, E and F represents bacterial strains in minimum salt medium and dibenzofuran ( $1 \mathrm{mM})$ as sole carbon source in the chemostat.

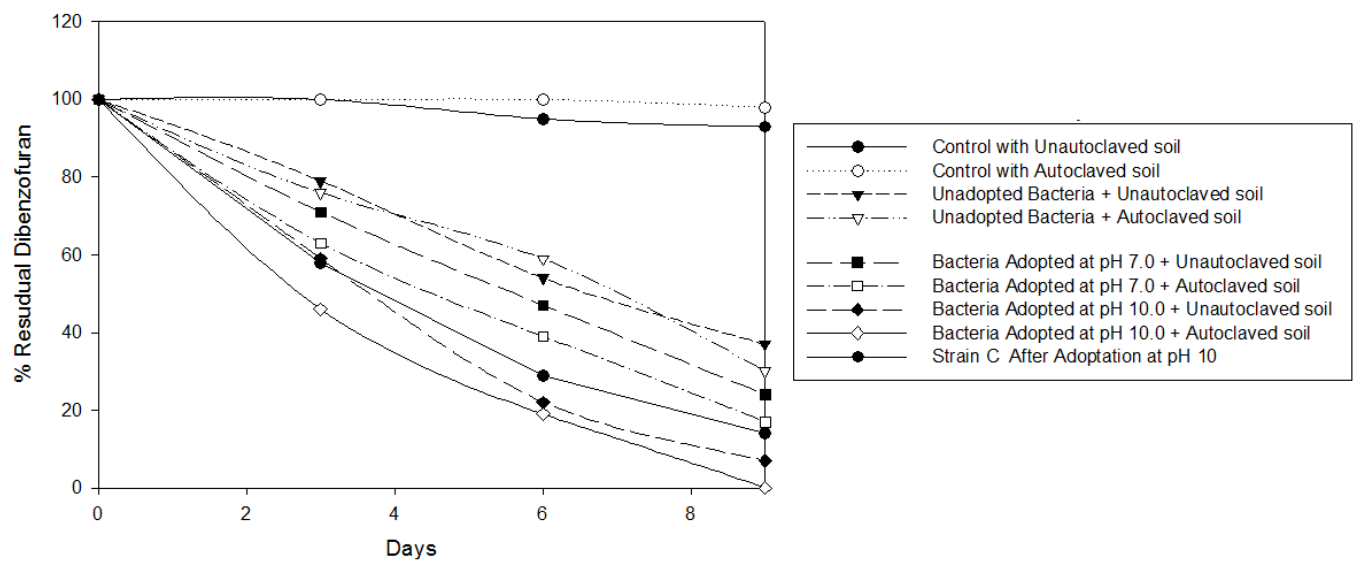

Figure 3. Degradation of dibenzofuran under different plans in microcosm along with controls. 


\section{Biodegradation of dibenzofuran in soil microcosm}

The in vivo efficiency of the community was tested through soil microcosm. After 90 days, the amount of dibenzofuran left in the soil was tested in each microcosm. Almost, no degradation was found in the case of control with autoclaved soil (microcosm A). The concentration of DBF in the soil at 0 days was taken as $100 \%$. Control with autoclaved soil (microcosm B) showed the presence of $70 \%$ DBF. Likewise, microcosm labelled as C, D, E, F, G, H showed 36.8\%, 36.59\%, $9.7 \%, 7.5 \%, 2.1 \%$ and $1.9 \%$ DBF respectively. Maximum degradation was seen in the case of microcosm inoculated with consortia adopted at $\mathrm{pH} 10$ as shown in Figure 3.

\section{Conclusion}

Microbial community isolated from sludge and sediment of pulp and paper mill was enriched in a chemostat with gradually increasing $\mathrm{pH}$ from 7 to 10 . Based on morphological dissimilarity, six strains were isolated from the chemostat at $\mathrm{pH} 7.0$ with the highest diversity on LB plates. One of these strains, strain $\mathrm{C}$, enriched at $\mathrm{pH} 10.0$ was found to be most efficient evaluated by growth rate and dibenzofuran degrading potency. The microbial community adapted in chemostat for different time duration was inoculated in soil microcosm. 180 days adapted community showed maximum degradation which makes it sufficient time for adaptation. GC analysis reflects that within 90 days, almost all dibenzofuran were metabolized. The best degradation results were shown by 180 days of adapted strain in a chemostat. Whereas 45 days and 90 days adapted community also showed significant results but not better than 180 days adapted community in a chemostat. The unadapted community is also degrading but not significantly as compared to the aforementioned community. This suggests that the microbial community adapted for a longer time in chemostat had better efficiency for the degradation of DBF. Degradation of dibenzofuran in soil microcosm indicates that the community is competent enough to survive and retain its degrading potency even in- situ conditions.

\section{Acknowledgment}

We thank the Council of Scientific and Industrial Research, New Delhi, India, for providing funds in the form of research projects.

\section{References}

APHA, AWWA, WEF. (2005). Spectrophotometric-single wavelength method in standard method for examination of water and waste water. Washington DC. 
Arun, A., Raja, P.P., Arthi, R., Ananthi, M., Kumar, K.S. and Eyini, M. (2008). Polycyclic aromatic hydrocarbons (PAHs) biodegradation by basidiomycetes fungi, Pseudomonas isolate, and their cocultures: comparative in vivo and in silico approach. Applied Biochemistry and Biotechnology, 151(2-3): 132-142.

Barkovskii, A.L. and Adriaens, P. (1996). Microbial dechlorination of historically present and freshly spiked chlorinated dioxins and diversity of dioxin-dechlorinating populations. Applied Environmental Microbiology, 62(12): 4556-4562.

Comeau, Y., Greer, C.W. and Samson, R. (1993). Role of inoculum preparation and density on the bioremediation of 2,4-D contaminated soil by bioaugmentation. Applied Microbiology and Biotechnology, 38: 681-687.

Fortnagel, P., Harms, H., Wittich, R. M., Krohn, S., Meyer, H., Sinnwell, V. and Francke, W. (1990). Metabolism of dibenzofuran by Pseudomonas sp. strain HH69 and the mixed culture HH27. Applied Environmental Microbiology, 56(4): 1148-1156.

Gautam, S.K., Sharma, R., Ahmad, A.H. and Thakur, I.S. (2003). Evaluation of pentachlorophenol-degrading potentiality of Pseudomonas sp. in soil microcosm. World Journal of Microbiology and Biotechnology, 19: 73-78.

Haack, S.K., Garchow, H., Klug, M.J. and Forney, L.J. (1995). Analysis of factors affecting the accuracy, reproducibility, and interpretation of microbial community carbon source utilization patterns. Applied Environmental Microbiology, 61(4): 1458 -1468 .

Iida, T., Mukouzaka, Y., Nakamura, K. and Kudo, T. (2002). Plasmid-borne genes code for an angular dioxygenase involved in dibenzofuran degradation by Terrabacter sp. strain YK3. Applied Environmental Microbiology, 68(8): 3716-3723.

Jaiswal, P.K. and Thakur, I.S. (2007) Isolation and characterization of dibenzofuran-degrading Serratia marcescens from alkalophilic bacterial consortium of the chemostat. Current Microbiology, 55: 447-454

Jaiswal, P.K., Kohli, S., Gopal, M. and Thakur, I.S. (2011). Isolation and characterization of alkalotolerant Pseudomonas sp. strain ISTDF1 for degradation of dibenzofuran. Journal of Industrial Microbiology and Biotechnology, 38: 503-511.

Kao, C.M., Chen, S.C., Liu, J.K. and Wu, M.J. (2001). Evaluation of TCDD biodegradaibility under different redox conditions. Chemosphere, 44: 1447-1454.

Kishino, T. and Bayashi, K. (1995). Relation between toxicity and accumulation of chlorophenols at various $\mathrm{pH}$, and their absorption mechanism in fish. Water Research, 29: 431-442.

Kumar, V., Thakur, R.K. and Kumar, P. (2019). Assessment of heavy metals uptake by cauliflower (Brassica oleracea var. botrytis) grown in integrated industrial effluent irrigated soils: A prediction modeling study. Scientia Horticulturae, 257, 108682.

Lafuente, R., Maymó-Gatell, X., Mas-Castellà, J. and Guerrero, R. (1996). Influence of environmental factors on plasmid transfer in soil microcosms. Current Microbiology, 32: 213-220

Mandal, P. (2005) Dioxin: a review of its environmental effects and its aryl hydrocarbon receptor biology. Journal of Comparative Physiology B, 175: 221-230.

Megharaj, M., Wittich, R.M., Blasco, R., Pieper, D.H. and Timmis, K.N. (1997) Superior survival and degradation of dibenzo-p -dioxin and dibenzofuran in soil by soil-adapted Sphingomonas sp. strain RW1. Applied Microbiology and Biotechnology, 48: 109-114.

Nojiri, H. and Omori, T. (2002) Molecular bases of aerobic bacterial degradation of dioxins: involvement of angular dioxygenation, Bioscience, Biotechnology, and Biochemistry, 66: 2001-2016.

Pearl, I.A. and Benson, H.K. (1940). The determination of lignin in sulfite pulping liquor. Paper Trade Journal, 111: 35-36.

Strubel, V., Engesser, K.H., Fischer P. and Knackmuss H.J. (1991). 3-(2- Hydroxyphenyl) catechol as substrate for proximal meta ring cleavage in dibenzofuran degradation by Brevibacterium sp. strain DPO 1361. Journal of Bacteriology, 173: 19321937.

Strubel, V., Rast, H.G., Fietz, W., Knackmuss, H.J. and Engesser, K.H. (1989). Enrichment of dibenzofuran utilizing bacteria with high co-metabolic potential towards dibenzodioxin and other anellated aromatics. FEMS Microbiology Letters, 49(23): $233-238$.

Thacker, N.P., Nitnaware, V.C., Das, S.K. and Devotta, S. (2007). Dioxin formation in pulp and paper mills of India. Environmental Science and Pollution Research - International, 14(4): 225-226.

Thakur I.S. (1995). Structural and functional characterization of a stable, 4 -chlorosalicylic acid degrading, bacterial community in a chemostat, World Journal of Microbiology and Biotechnology. 11: 643-645. 
Viñas, M., Sabate', J., Espuny, M.J. and Solanas, A.M. (2005) Bacterial community dynamics and polycyclic aromatic hydrocarbon degradation during bioremediation of heavily creosote-contaminated soil. Applied Environmental Microbiology, 71 (11): 7008-7018.

Wittich, R.M., Wilkes, H., Sinnwell, V., Francke, W. and Fortnagel, P. (1992). Metabolism of dibenzo-p-dioxin by Sphingomonas sp. strain RW1. Applied Environmental Microbiology, 58: 1005-1010.

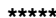

Cite this chapter as: Sahni, S. (2020). Alkalotolerant consortium as a potential degrader of dioxin-like compounds of pulp and paper mill wastewater. In: Environmental Degradation: Causes and Remediation Strategies, Volume 1, Eds. Kumar, V., Singh, J. and Kumar, P., pp. 76-87, https://doi.org/10.26832/aesa-2020-edcrs-06 